\title{
PENGALAMAN ADAPTASI SURVIVOR SCHIZOPHRENIA PASCA PERAWATAN DI RUMAH SAKIT
}

\author{
Susanti Niman*, Febri Christian \\ Sekolah Tinggi Ilmu Kesehatan Santo Borromeus, Jln Parahyangan Kavling 8 Blok B No.1, Kota Baru Parahyangan, \\ Padalarang, Kabupaten Bandung Barat, Jawa Barat, Indonesia 40553 \\ *susantiniman@gmail.com
}

\begin{abstract}
ABSTRAK
Schizophrenia adalah gangguan jiwa berat ditandai dengan perubahan pada persepsi, pikiran, afek, dan perilaku seseorang. Gejala schizophrenia berlangsung selama jangka waktu minimum satu bulan dan kemunduran fungsi berlangsung minimum selama enam bulan dengan tingkat kekambuhan $70-82 \%$. Penderita schizophrenia sering ditemukan kurang mendapat dukungan sosial dalam mengoptimalkan proses rehabilitasi setelah menjalani perawatan di Rumah Sakit. Tujuan studi untuk mengekplorasi pengalaman survivor schizophrenia beradaptasi pasca rawat. Metode penelitian kualitatif dengan pendekatan deskriptif fenomenologi terhadap 10 informan. Hasil ditemukan 5 tema adaptasi pasca perawatan di rumah sakit yaitu cara menghadapi suatu permasalahan, memiliki pekerjaan setelah keluar dari rumah sakit jiwa, dukungan keluarga, dukungan lingkungan dan dukungan tenaga kesehatan. Kesimpulan adaptasi survivor schizophrenia pasca perawatan di rumah sakit membutuhkan kemampuan problem solving, dukungan dari keluarga dan masyarakat.
\end{abstract}

Kata kunci: adaptasi, pengalaman, schizophrenia, survivor

\section{THE EXPERIENCE OF SCHIZOPHRENIA SURVIVOR ADAPTATION POST-CARE IN HOSPITAL}

\begin{abstract}
Schizophrenia is a severe mental disorder characterized by changes in a person's perceptions, thoughts, affect, and behaviour. Schizophrenia symptoms last for a minimum period of one month and deterioration of function lasts for a minimum of six months with a recurrence rate of $70-82 \%$. Schizophrenia sufferers are often found to lack social support in optimizing the rehabilitation process after undergoing treatment at the hospital. Purpose to explore the experience of survivor schizophrenia adapting post-treatment. Method Qualitative with a phenomenological descriptive approach to 10 informants. Results found 5 adaptation post-treatment themes in the hospital namely how to deal with a problem, having a job after leaving the mental hospital, family support, environmental support and support of health workers. Conclusion: Adaptation of post-treatment schizophrenia survivors in hospital requires problem-solving skills, support from family and community.
\end{abstract}

Keywords: adaptation, experience, schizophrenia, survivor

\section{PENDAHULUAN}

Skizofrenia merupakan gangguan jiwa berat dengan berbagai gejala kejiwaan termasuk gejala positif waham dan halusinasi serta gejala negatif avolisi dan menarik diri, gangguan kognitif dan disregulasi emosi. Obat farmakologis telah menjadi andalan bagi pasien dengan penyakit ini, tetapi hanya sepertiga yang berhasil pulih ke tingkat fungsi awal tanpa gejala psikotik yang signifikan, sebagian besar memiliki beberapa gejala sisa, dan gejala sering kambuh selama pada jangka panjang. Bahkan gejala berulang sering menunjukkan tidak respons terhadap antipsikotik (Kanahara,Yamanaka, Suzuki, Takase, \& Iyo, 2018).
Skizofrenia adalah salah satu gangguan mental penyebab disabilitas dan bersifat persisten. Hal tersebut ditandai dengan perjalanan yang parah, berulang dengan sejumlah gejala. Selain itu, skizofrenia menyebabkan gangguan fungsional dalam banyak dimensi seperti hubungan interpersonal, perawatan diri dan bekerja. Prevalensi skizofrenia seumur hidup adalah sekitar $1 \%$ dan pasien sering mendapatkan stigmatisasi dan penolakan sosial. Pasien skizofrenia membutuhkan perawatan jangka panjang dan komprehensif sehingga berdampak pada beban ekonomi. Hal itu terjadi karena skizofrenia berdampak luas, tidak hanya untuk pasien itu sendiri tetapi juga keluarga dan masyarakat. Skizofrenia bila dihitung dari beban 
ekonomi dapat menjadi penyakit paling mahal di antara semua gangguan kejiwaan dalam hal pembiayaan perawatan per pasien (Zaprutko, Göder, Kus, Rakhman, Bilobryvka, \& Nowakowska, 2016). Pasien skizofrenia sering mendapat stigma berbahaya, tidak dapat diprediksi, melakukan kekerasan dan rentan terhadap kejahatan. Stigma dapat berdampak negatif pada pasien dan keluarga yang akhirnya menghambat proses pemulihan pasien (Hsiao, Lu, \& Tsai, 2019).

Riset Kesehatan Dasar (Riskesdas) Nasional pada tahun 2018 adalah prevalensi rumah tangga dengan ART gangguan jiwa/skizofrenia sebesar 7.1\% permil sedangkan Jawa Barat sebesar 6.3\% permil. Bagian terpenting dari sebuah program pengobatan di rumah sakit jiwa terhadap pasien dengan gangguan jiwa adalah perencanaan pulang. Program perencanaan pulang berkaitan dengan bentuk usaha kerjasama antara tim kesehatan, keluarga, klien dan orang yang penting bagi pasien. Sebelum pasien pulang hal yang perlu dipersiapkan adalah aktivitas hidup sehari-hari, tingkat kebutuhan perawatan, pengetahuan dan kemampuan pasien dan keluarga, hubungan interpersonal dalam keluarga, kemampuan serta kemauan pasien dan keluarga dalam penerimaan tindakan keperawatan, sumber dan sistem pendukung yang ada di masyarakat, sumber finansial dan pekerjaan (Yosep, 2014). Bila semua hal itu telah terpenuhi maka tidak masalah dalam pengembalian pasien ke masyarakat.

Rehabilitasi menurut Foundation of Psychiatric Mental Health Nursing dirancang sebagai sebuah program dimana menyediakan pelayanan kepada klien agar dapat meningkatkan kemampuan bersosialisasi, meningkatkan kemandirian dan kualitas hidup, serta keterampilan bekerja. Rehabilitasi di rumah sakit jiwa dipersiapkan untuk klien setelah pulang agar memudahkan dalam beradaptasi ketika kembali ke lingkungannya serta untuk menghadapi stigma buruk dari masyarakat (Yosep, 2014). Sebagai fase terakhir dalam pelayanan di rumah sakit jiwa, rehabilitasi memiliki tim seleksi kesehatan yang terdiri dari dokter, perawat jiwa, psikolog dan social worker. Perawat jiwa memiliki peranan penting dalam proses seleksi tersebut, peran tersebut sebagai role model, kolaboratif (dokter, psikolog, social worker), leader terhadap modalitas, pengkajian keluarga, melatih koping yang konstruktif, melibatkan keluarga dan tokoh masyarakat, memilih kegiatan yang sesuai dan melakukan penyuluhan terhadap keluarga.
Recovery pasien skizofrenia ditandai dengan kondisi pasien yang mampu hidup secara otonomi, memiliki kontribusi dan merasa puas terhadap lingkungannya. Recovery dapat dilihat dari domain kehidupan yang penting bagi pasien biasanya terkait dengan kemajuan dalam kegiatan normatif seperti pendidikan, pekerjaan, perumahan dan hubungan sosial. Otonomi dan pilihan dalam perawatan kesehatan jiwa dianggap penting dalam konsep recovery (Whitley, Palmer, \& Gunn, 2015).

Skizofrenia bersifat kronis dengan gangguan yang memburuk. Namun tingkat recovery skizofrenia adalah 20-25\% pemulihan total, $40-45 \%$ mencapai pemulihan sosial (kemandirian ekonomi, perumahan dan gangguan sosial yang rendah) dan hanya 30-40\% sisanya yang tetap buruk. Recovery dapat dilihat dari kurangnya kebutuhan untuk perawatan kesehatan jiwa, menggunakan layanan dan obat-obatan pada tingkat yang diperlukan untuk mempertahankana kehidupan yang stabil atau bahagia. Recovery dapat didefinisikan sebagai kemampuan untuk secara memadai memenuhi kewajiban peran meskipun ada beberapa batasan dalam fungsi (Green, 2004).

Manajemen perawatan pasien skizofrenia tidak hanya bertujuan mencapai perbaikan klinis jangka pendek dan remisi jangka panjang tetapi juga mempertahankan fungsi fisik dan mental bersamaan dengan meningkatkan quality of life dan pemulihan pasien. Fokus utama perawatan skizofrenia adalah memaksimalkan kualitas hidup, fungsi adaptif dan membantu pasien dalam mencapai tujuan hidup pribadi (dalam pekerjaan, perumahan dan hubungan pribadi) (Pietrini et al., 2019).

Organisasi Kesehatan Dunia (WHO) memperkirakan bahwa satu dari empat keluarga memiliki satu anggota keluarga dengan gangguan kejiwaan karena itu, anggota keluarga merupakan caregiver utama yang merawat anggota keluarga yang gangguan jiwa (Rahmani, Ranjbar, Hosseinzadeh, Razavi, Dickens, \& Vahidi, 2019).

Pasien dengan gangguan jiwa meskipun telah keluar dari rumah sakit jiwa tetap akan menerima stigma negatif dari masyarakat. Pandangan masyarakat terhadap pasien gangguan jiwa adalah tidak bisa disembuhkan meskipun minum obat terus. Pandangan ini harus diubah karena faktor yang berkaitan dengan kekambuhan adalah komorbiditas, kepatuhan terhadap pengobatan yang buruk, penggunaan narkoba, pengalaman 
hidup penuh tekanan, efek samping pengobatan, hidup sendiri, status sosial ekonomi rendah, dukungan sosial yang buruk, keterlambatan dalam mencari perawatan, kurangnya kunjungan ke rumah oleh petugas kesehatan dan stigma yang melekat (Adebiyi, Mosaku, Irinoye \& Oyelade, 2018). Dengan kata lain kesembuhan pasien sangat dipengaruhi kepatuhan terhadap program pengobatan. Sedangkan, kepatuhan dipengaruhi oleh support sistem keluarga, pengetahuan, ketersediaan atau keterjangkauan fasilitas kesehatan dan sikap petugas tenaga kesehatan dalam membantu proses penyembuhan serta mencegah pasien gangguan jiwa untuk reopname .

Relaps adalah regresi ke fase sebelum fase stabil. Pasien skizofrenia mengalami kekambuhan bila ditemukan kembalinya gejala setelah periode perbaikan.Relaps mungkin memberikan gejala yang berbeda dari sebelumnya sehingga membutuhkan intervensi yang lebih besar (Adebiyi, Mosaku, Irinoye \& Oyelade, 2018). Kambuh merupakan hal yang sangat rentan terjadi pada klien dengan gangguan jiwa setelah mereka kembali ke lingkungannya pasca menjalani pengobatan di rumah sakit jiwa. Gangguan jiwa kronis mengalami kekambuhan sebesar 50\% pada tahun pertama dan $70 \%$ pada tahun kedua (Yosep, 2014).

Koping yang efektif dapat membantu seseorang dalam menerima dan menoleransi tekanan yang didapatnya, serta tidak menghiraukan tekanan yang diluar batas penerimaannya, namun apabila koping maladaptif yang dilakukan berarti individu tersebut tidak mampu menghadapi rintangan maupun tekanan yang dialaminya secara positif sehingga dapat menyebabkan masalah yang lebih lanjut (Tan, 2011). Pasien gangguan jiwa yang memiliki koping adaptif yang tinggi akan memiliki kualitas hidup yang tinggi pula, sebaliknya bila koping adaptif mereka rendah, maka kualitas hidup mereka rendah pula (Rubbyana, 2012). Pasien gangguan jiwa pasca rawat inap dapat memaknai hidupnya dan sangat bergantung pada tanggung jawab dari status mereka masing-masing (Putri \& Ambarini, 2012).

Ada banyak hal yang mempengaruhi proses recovery dan tingginya kekambuhan pasien schizofrenia menjadi dasar untuk melakukan penelitian tentang apa yang membuat pasien schizofrenia tidak mengalami kekambuhan setelah satu tahun perawatan di rumah sakit sehingga dapat menjadi dasar untuk intervensi perawat dalam menurunkan kekambuhan pasien. Adapun tujuan penelitian adalah untuk mengeksplorasi bagaimana pengalaman klien schizophrenia untuk dapat beradaptasi pasca rawat di rumah sakit jiwa melalui penelitian kualitataif.

\section{METODE}

Peneliti menggunakan metode kualitatif dan desain penelitian deskriptif dengan pendekatan fenomenologi. Peneliti menggunakan wawancara semi terstruktur pada 10 orang informan yang menjadi anggota KPSI paguyuban Bandung dengan pengalaman dirawat di RSJ dan masih menjalani pengobatan. Pedoman wawancara berisi tentang bagaimana informan mengatasi masalah yanga dialami, kegiatan yang dilakukan oleh informan dan cara supaya tidak kembali dirawat. Data hasil wawancara dilakukan analisa dengan melakukan abstraksi data yang meliputi pemberian koding dan klasifikasi, menyaring dan menyusun tema sementara kemudian melakukan interpretasi data sehingga tema sementara dapat dikelompokkan ke dalam unit analisis data yang lebih besar untuk dapat dihasilkan tema.

\section{HASIL}

Tema yang didapatkan dari hasil penelitian adalah sebagai berikut :

1. Cara menghadapi suatu permasalahan

Semua informan mengungkapkan saat menghadapi suatu permasalahan informan melakukan berdasarkan apa yang telah dilatihkan di rumah sakit dan meminta saran dari orang yang dipercaya oleh informan.

"Kalau saya meminta dan mendengarkan saran dari Ustad tempat saya tinggal...pokoknya terima aja dulu kondisi bahwa saya teh udah sakit, tapi sekarang udah sadar dan saya mau membuktikan ke masyarakat bahwa saya bisa ini itu...gitu aja...akhirnya kaya gini lah sekarang..."(informan 1).

"Dulu waktu sakit, kalau ada yang bikin kesel kedengaran ada yang ngebisikan di telinga jelas banget nyuruh pukul, pukul yang bikin kesel... tapi alhamdulillah sekarang mah kalau ada yang ngeselin yah udah biarin aja tarik nafas kesel juga kurang keselnya... dibawa happy aja...atau dibawa doa biar hati jadi tenang.. ".(informan 2)

"Kalau saya mengatasi masalah dengan cara saya pikir sendiri dan dicari jalan keluarnya...kalau terkait dengan penyakit... saya punya nomor kontak dokternya jadi kalau ada apa - apa saya suka nanya gini gitu...alhamdulilah selalu dijawab sama dokternya”...(informan 4) 
2. Memiliki pekerjaan setelah pulang dari rumah sakit jiwa

Semua informan mengungkapkan sudah bekerja dan memiliki kesibukan.

"Sebelum sakit saya sempat kerja di luar kota...setelah keluar dari rumah sakit saya kerja di tetangga yang bisnis air isi ulang...terus karena ada lowongan jadi photographer di tempat lain saya coba - coba karena memang sesuai kriteria lulusan SMA, usia dibawah 35 tahun dan bisa bahasa Inggris. Alhamdulilah saya lolos...tapi kerjanya capek saya nggak tahan jadi keluar...Kalau sekarang udah kerja lagi di konveksi...nyablon..." (informan 5).

"Keluar dari rumah sakit jiwa langsung ngamen.ya seminggulah. Semingu berhenti disuruh tenang dulu sama adik, disuruh minum obat yang teratur dulu. saya tuh ikut di Karang Taruna jadi humas. Selain di Karang Taruna juga di RT saya dijadiin humas juga gitu..Setiap bulan saya disuruh narik iuran gitu... Dikasih 10\%, udah gitu sehari-harinya kadang-kadang kalo misalkan gas udah abis saya yang disuruh.Ya, alhamdulilah dikasih makan, dikasih minum, dikasih uang juga gitu. Selain itu kalo misalkan ada orang yang lagi bikin rumah, ikut gitu, jadi kuli-kuli ajalah..ngaduk semen...ngecor pokoknya apa saja “...(informan 6).

"Ya meskipun dengan IPK biasalah gitu yaa paspasan, dah tapi dengan itu alhamdulilah ya itulah jalan Allah ya ditahun dulu saya masih bisa ikut ujian dan lulus jadi karyawan di salah satu sekolah" ...(informan 7).

\section{Dukungan keluarga}

Partisipan mengungkapkan bahwa keluarga memahami penyakit yang dialami oleh partisipan dan selalu membantu dalam proses penyembuhan partisipan.

"Alhamdulilah keluarga semua tahu tentang kondisi penyakit saya, karena saya anak bungsu. Bapak, Kakak, nganterin kalo rawat jalan. Terus selalu ingetin jangan sampai ngelamun lagi dan harus banyak ngobrol’...(informan 8).

"Paling pertama ya dukungan dari keluargalah ya... jadi saya ngerasa semangat gitu...Jangan telat obat katanya, jangan lupa makan,kata keluarga... Kalo saya emang dulu suka diantar sama si bapak. Kalo dirumah sama mamah, sekarang kan mamah udah nggak ada, kadang kadang sama bapak. Kalo dianter sama bapak saya suka nyetir gitu.. kalo bapak nggak ya saya sendiri yang berangkat. Emang keluarga ya kalo saya minta anter, pasti dianter gitu'...(informan 9).

"Peran keluarga misalnya ketika saya nggak bisa keluar naik motor, atau naik mobil, nganterin pake kendaraan, Ngajak ngobrol ketika saya nggak ada temen, Nanyain minum obat, Schedule minum obat...scheduling ke dokter kadang-kadang ngambilin obat... bayarin obat-obat karena mahal banget nggak kuat dan segala macem"...(informan 10).

\section{Dukungan lingkungan}

Semua partisipan merasakan lingkungan tempat tinggal partisipan sangat mendukung proses penyembuhan partisipan.

"Alhamdulilah-nya kan rumah deket Masjid rumah, jadi sering ke masjid ngobrol aja sama bapak-bapak, ngobrol aja... Alhamdulilah-nya teh nggak nganggap saya sakit gitu...Biasa aja gitu"...(informan 3).

"Temen saya selalu memperhatikan...teman saya tahun kondisi saya dan membantu saya bahkan mereka akan nelpon kakak saya, karena ternyata teman - teman saya tahu nomor kakak saya"...saya nggak pernah merasa dijauhin atau dikucilkan"...(informan 5).

"lingkungan tempat saya tinggal enak, jadi saya ngerasa semangat gitu. Oang lain yang udah tau tentang saya pada ngasih semangat ke saya. Walau saya dulu suka mukul, suka ngamukngamuk. Sekarang mah alhamdulilah gitu.. tetangga semuanya udah pada tau kalo keliatan saya sakit langsung kasih tau ke orang tua"...(informan 2).

\section{Dukungan tenaga kesehatan}

Partisipan merasakan adanya dukungan dari tenaga kesehatan yang membantu proses kesembuhan partisipan.

"Ada psikolog,hubungan baik antara psikolog dengan psikiater saya dan hubungan baik dengan hypnoterapis dan keluarga saya juga. Kayak net yang menopang kita sendiri ke atas...Jadi untungnya mereka semua kooperatif...menopang gitu kan untuk saya sembuh"...(informan 4).

"Ada perlombaan tenis meja, Saya ikut, ikut tenis meja sama temen saya namanya Abdulah. Bertanding, Alhamdulilah saya yang jadi juaranya gitu. Kata perawat dipromosikan, udah 
aja ikut ke Lawang, Malang. Pas single-nya, saya kalah tapi, double-nya saya juara tiga gitu sama temen saya. pokoknya sangat membantu kesembuhan saya"...(informan 7).

"Kalo saya saat diinterview sama dokter. kalo ada keluhan bilang aja ke dokter jadi, nggak pernah disembunyiin gitu. Terus dokternya enak diceritain lagi sama saya terkait dosis obat saya...jadinya semangat terus buat berobat"...(informan 10).

\section{PEMBAHASAN}

1. Cara menghadapi suatu permasalahan

Seluruh informan menyatakan bahwa mereka mampu menghadapi masalah mereka dengan berbagai cara, seperti meminta saran atau pendapat dari orang lain dan dengan caranya masing-masing. Di lihat dari hal tersebut informan telah menggunakan strategi koping yang berfokus pada masalah dan menggunakan strategi koping yang adaptif dengan cara mencari informasi dan meminta saran. Menghadapi suatu permasalahan membutuhkan kemampuan mekanisme koping yang efektif. Spiritualitas merupakan sumber koping yang penting yang dapat meningkatkan kesejahteraan psikososial dan kesehatan mental bagi individu dengan penyakit jiwa berat. Spiritualitas telah didefinisikan sebagai proses mempromosikan peluang untuk membangun koneksi pribadi yang bermakna, apakah koneksi ini dengan diri sendiri, orang lain, alam, atau kekuatan yang lebih tinggi (Subica, \& Yamada,2018).

Koping adalah proses bagaimana individu merespon dan bertindak saat mengalami masalah dan saat terpapar oleh stres (Rahmani, Ranjbar, Hosseinzadeh, Razavi, Dickens, \& Vahidi, 2019). Pasien gangguan jiwa ketika keluar dari rumah sakit jiwa akan kembali ke lingkungan tempat tinggalnya dan berhadapan dengan berbagai situasi. Sering pasien ketika fase recovery dan dikembalikan ke lingkungan tempat tinggalnya, pasien memiliki kepercayaan diri yang rendah untuk dapat kembali normal. Hal ini merupakan akibat adanya sisa stress dan trauma ketika awal rehabilitasi. dan ketika menyadari mereka tidak memiliki sumber penghasilan. Beberapa pasien gangguan jiwa sering ditemukan hanya memiliki sedikit koneksi atau kerabat sehingga mereka kurang dalam mendapatkan dukungan sosial dalam mengoptimalkan proses rehabilitasi. Mereka juga sering mendapatkan stigma negatif di masyarakat serta akibat penggunaan obat secara terus-menerus yang berdampak pada kepasifan mereka, menjadikan hal tersebut sebagai suatu tantangan untuk dapat sembuh.

2. Memiliki pekerjaan setelah pulang dari rumah sakit jiwa

Seluruh informan menyatakan bahwa mereka memiliki pekerjaan seperti sebagai karyawan konveksi, kerja bangunan, kerja di bagian pameran, karyawan di sekolah, kerja dibidang jasa. Intervensi terapi okupasi efektif dalam mencegah rehospitalisasi dan meningkatkan fungsi kognitif pasien Skizofrenia. Fungsi kognitif pada pasien Skizofrenia memiliki hubungan kuat dengan fungsi sosial, insight dan kepatuhan terapi (Shimada, Nishi, Yoshida, Tanaka, \& Kobayashi, 2016).

Permasalahan pasien gangguan jiwa sering mendapatkan stigma negatif . Padahal pasien pasca rawat dari rumah sakit jiwa dapat kembali produktif dengan bekerja di tengah lingkungan masyarakat sebagaimana mestinya asalkan mendapatkan kesempatan. Informan menyatakan bahwa mereka memiliki kemauan untuk bekerja sehingga dapat menafkahi diri sendiri dan keluarganya. Informan mengatakan dengan bekerja dapat mengalihkan mereka dari halusinasi.Harapan informan terkait tempat kerja adalah tempat yang dapat mengerti mereka yakni dengan memberikan maklum apabila mereka harus pergi kontrol ke rumah sakit setiap bulannya. 2 informan menyatakan bahwa mereka memiliki keinginan untuk bisa memberdayakan orang-orang dengan gangguan jiwa untuk dapat berwirausaha. Informan mengungkapkan ingin membuat pelatihan atau balai kerja untuk merangkul klien gangguan jiwa lainnya yang telah keluar dari rumah sakit jiwa.

\section{Dukungan keluarga}

Dukungan keluarga adalah bagaimana keluarga berperan dalam membantu proses adaptasi pasien setelah keluar dari rumah sakit jiwa. Keluarga terdiri dari orang tua, saudara kandung, pasangan dan keluarga besar secara umum. Semua informan menyatakan bahwa mereka mendapatkan dukungan dari keluarga. Proses perawatan yang melibatkan pasien dan keluarga akan membantu proses intervensi dan menjaga agar pasien tidak kambuh lagi setelah pulang (Yosep, 2014). Keluarga adalah bagian yang paling dekat dengan pasien dan melakukan perawatan utama bagi pasien. Keluarga berperan dalam menentukan cara atau asuhan yang diperlukan di rumah. Keberhasilan perawat dirumah sakit dapat sia sia jika tidak berlanjut di rumah yang kemudian 
mengakibatkan pasien harus di rawat kembali. Peran serta keluarga sejak awal asuhan di rumah sakit akan meningkatkan kemampuan keluarga merawat klien dirumah sehingga kemungkinan kambuh dapat dicegah.

Dukungan keluarga sangat dibutuhkan oleh pasien, karena keluarga menjadi sumber informasi yang pertama bagi pasien. Dukungan informasi keluarga dengan kemampuan pasien mengatasi tanda dan gejala skizofrenia residual memiliki hubungan yang signifikan (Niman, 2017). Keluarga memegang peran penting dalam mendukung proses adaptasi survivor skizofrenia setelah keluar dari rumah sakit jiwa.

Bentuk peran keluarga dapat ditunjukkan melalui penerimaan keluarga terhadap anggota keluarga pasca rawat dan tidak membeda-bedakan survivor dengan anggota keluarga lainnya. Suasana rumah dimodifikasi dengan cara tidak mengacuhkan anggota keluarga yang mengalami gangguan jiwa dan mengikutsertakan anggota keluarga dengan gangguan jiwa dalam berbagai aktivitas (Niman, 2019). Informan menyatakan bahwa keluarganya memberikan mereka kesempatan untuk bekerja, sehingga mereka melatih diri untuk mau berusaha. Selain itu keluarga juga selalu mengingatkan untuk teratur menjalani pengobatan, mau untuk mengantarkan dan menjemput kontrol ke rumah sakit jiwa, dan ada juga yang mensupport secara finansial, dimana keluarga mau memberikan biaya pengobatan.

\section{Dukungan lingkungan}

Dukungan lingkungan adalah dukungan yang berasal dari orang lain selain keluarga, seperti teman, tetangga, dan lingkungan tempat kerja. Seluruh informan menyatakan bahwa mereka mendapat dukungan dari lingkungan.

Tantangan terbesar untuk penanganan schizofrenia pasca di rawat dari rumah sakit terletak pada keluarga dan masyarakat. Masyarakat harus mampu menerima pasien setelah pulang dari rumah sakit, melibatkannya dalam kegiatan masyarakat, dan yang paling penting memantau perilaku klien. Lingkungan tempat tinggal sangat mempengaruhi klien. Klien yang tinggal di lingkungan yang kurang baik di masyarakat akan meninggalkan masyarakat atau kembali ke rumah sakit (Videbeck, 2008).

Lingkungan yang tidak memberikan dukungan terhadap orang dengan gangguan jiwa setelah keluar dari rumah sakit jiwa dapat menjadi salah satu faktor adanya kekambuhan berulang. Dalam penelitian ini seluruh informan mengungkapkan bahwa mereka mendapat dukungan dari lingkungan, seperti diberikan kesempatan untuk melakukan pekerjaan yang sesuai kemampuannya, diberikan tempat tinggal, diberikan motivasi seperti semangat dan secara spiritual, diikutsertakan dalam kegiatan-kegiatan yang dilaksanakan. Yang paling penting adalah bagaimana lingkungan dapat menerima mereka setelah keluar dari rumah sakit jiwa dengan tidak memberikan stigma negatif kalau mereka tidak mampu melakukan aktifitas atau berkegiatan secara biasa.

\section{Dukungan tenaga kesehatan}

Tenaga kesehatan berperan dalam membantu proses adaptasi pasien setelah keluar dari rumah sakit jiwa. Tenaga kesehatan memiliki tugas memberikan informasi pada pasien dan keluarga serta memberikan konseling (Keliat, Akemat, Daulima,Nurhaeni, 2011). Seluruh informan menyatakan bahwa mereka mendapat dukungan dari tenaga kesehatan. Tenaga kesehatan memiliki peran untuk memfasilitasi kemampuan klien dalam beradaptasi dan menghadapi perubahan. Informan mengungkapkan dengan adanya hubungan yang baik antara mereka dengan tenaga kesehatan sangat membantu sekali. Informan menceritakan, ketika ada hal yang tidak dia ketahui cara penanganannya, mereka dengan mudah dapat menghubungi tenaga kesehatan tanpa harus langsung ke rumah sakit jiwa.

\section{SIMPULAN}

Pengalaman klien schizophrenia untuk dapat beradaptasi pasca rawat di rumah sakit jiwa dilakukan dengan mencoba menyelesaikan masalah yang dialami dengan mencari informasi dari tenaga kesehatan dan meminta saran dari orang yang dipercaya, adanya keluarga yang membantu, memiliki pekerjaan, lingkungan tidak mengucilkan dan selalu berkomunkasi dengan tenaga kesehatan.

\section{DAFTAR PUSTAKA}

Adebiyi, M. O., Mosaku, S. K., Irinoye, O. O., \& Oyelade, O. O. (2018). Socio-demographic and clinical factors associated with relapse in mental illness. International Journal of Africa Nursing Sciences, 8(May), 149-153. https://doi.org/10.1016/j.ijans.2018.05.007

Badan Penelitian dan Pengembangan Kesehatan. (2019). Laporan Hasil Riset Kesehatan Dasar (Riskesdas) Indonesia tahun 2018. 
Riset Kesehatan Dasar 2018, pp. 182-183. Retrieved from https://www.litbang.kemkes.go.id/laporanriset-kesehatan-dasar-riskesdas/

Green, C. A. (2004). Fostering Recovery from Life-transforming Mental Health Disorders: A Synthesis and Model. Social Theory and Health, 2(4), 293-314. https://doi.org/10.1057/palgrave.sth.870003 6.

Hsiao, C. Y., Lu, H. L., \& Tsai, Y. F. (2019). Factors Associated With Primary Family Caregivers' Perceptions on Quality of Family-Centered Care in Mental Health Practice. Journal of Nursing Scholarship, 51(6), 680-688. https://doi.org/10.1111/jnu.12526

Kanahara, N., Yamanaka, H., Suzuki, T., Takase, M., \& Iyo, M. (2018). First-episode psychosis in treatment- resistant schizophrenia : a cross-sectional study of a long-term follow-up cohort. 1-11.

Keliat, B. A.,Akemat,,Daulima,C. H. N.,Nurhaeni, H. (2011). Keperawatan Kesehatan Jiwa Komunitas: CMHN (Basic Course). Jakarta: EGC

Putri, Prahastia K. \& Ambarini, Tri K. (2012). Makna Hidup Penderita Skizofrenia Pasca Rawat Inap

Niman, S. (2019). THE PHENOMENON OF FAMILY CAREGIVER EXPERIENCE IN CARING FOR FAMILIES WITH MENTAL DISORDERS . In Jurnal Keperawatan Jiwa (Vol. 7). https://doi.org/10.26714/jkj.7.1.2019.19-26

Niman, S. (2017). Hubungan dukungan informasi keluarga dengan kemampuan klien mengatasi tanda dan gejala skizofrenia residual. Jurnal Kesehatan "Caring and Enthusiasm," 1. https://doi.org/: 977-23387823-01

Pietrini, F., Albert, U., Ballerini, A., Calò, P., Maina, G., Pinna, F., Vaggi, M., Boggian,I., Fontana, M., Moro, C., Carpiniello, B. (2019). The modern perspective for longacting injectables antipsychotics in the patient-centered care of schizophrenia. Neuropsychiatric Disease and Treatment,
15 ,

$1045-1060$

https://doi.org/10.2147/NDT.S199048

Rahmani, F., Ranjbar, F., Hosseinzadeh, M., Razavi, S. S., Dickens, G. L., \& Vahidi, M. (2019). Coping strategies of family caregivers of patients with schizophrenia in Iran: A cross-sectional survey. International Journal of Nursing Sciences, 6(2), 148-153. https://doi.org/10.1016/j.ijnss.2019.03.006

Rubbyana, Urifah. (2012). Hubungan antara Strategi Koping dengan Kualitas Hidup pada Penderita

Skizofrenia Remisi Simtom. E- Journal of UNAIR

Shimada, T., Nishi, A., Yoshida, T., Tanaka, S., \& Kobayashi, M. (2016). Factors Influencing Rehospitalisation of Patients with Schizophrenia in Japan: A 1-year Longitudinal Study. Hong Kong Journal of Occupational Therapy, 28, 7-14. https://doi.org/10.1016/j.hkjot.2016.10.002

Subica, A. M., \& Yamada, A. M. (2018). Development of a spirituality-infused cognitive behavioral intervention for individuals with serious mental illnesses. Psychiatric Rehabilitation Journal, 41(1), 8-15. https://doi.org/10.1037/prj0000102

Stuart, Gail W., \& Michele T. Laraia. (2001). Principles and Practice of Psychiatric Nursing $7^{\text {th }}$ Ed. St.

Louis, Missouri: Elsevier Mosby.

Tan, Gabriel. (2011). Adaptive Versus Maladaptive Coping and Belief and Their Relation to Cronic Pain

Adjusment. The Clinical Journal of Pain.

Townsend, Mary C. (2009). Psychiatric Mental Health Nursing: Concepts of Care in Evidence-Based Practice. Philadelphia: F.A. Davis Company

Videbeck, Sheila L. (2008). Psychiatric Mental Health Nursing $2^{\text {nd }} \quad E d$. Philippine: Lippincott Williams \& Wilkins

Whitley, R., Palmer, V., \& Gunn, J. (2015). Recovery from severe mental illness. Cmaj, 187(13), 951-952. https://doi.org/10.1503/cmaj.141558 
Yosep, Iyus. (2014). Keperawatan Jiwa (edisi revisi). Bandung: PT. Refika Aditama

Zaprutko, T., Göder, R., Kus, K., Rakhman, L., Bilobryvka, R., \& Nowakowska, E. (2016). The Cost of Inpatient Care of Schizophrenia and Treatment Schedules Used in German Academic Center: Kiel. Psychiatric Quarterly, 87(4), 595-603. https://doi.org/10.1007/s11126-015-9412-0 